\title{
Hsp104 antagonizes $\alpha$-synuclein aggregation and reduces dopaminergic degeneration in a rat model of Parkinson disease
}

\author{
Christophe Lo Bianco,,1,2 James Shorter, ${ }^{3}$ Etienne Régulier, ${ }^{2}$ Hilal Lashuel,2 ${ }^{2}$ akeshi Iwatsubo, ${ }^{4}$ \\ Susan Lindquist, ${ }^{5}$ and Patrick Aebischer ${ }^{2}$

\begin{abstract}
${ }^{1}$ Wallenberg Neuroscience Center, Division of Neurobiology, Department of Experimental Medical Science, Lund University, Lund, Sweden. 2Brain Mind Institute, Ecole Polytechnique Fédérale de Lausanne, Lausanne, Switzerland. ${ }^{3}$ Department of Biochemistry and Biophysics, University of Pennsylvania School of Medicine, Philadelphia, Pennsylvania, USA. ${ }^{4}$ Department of Neuropathology and Neuroscience, Graduate School of Pharmaceutical Sciences, University of Tokyo, Tokyo, Japan. ${ }^{5}$ Howard Hughes Medical Institute, Whitehead Institute for Biomedical Research, Cambridge, Massachusetts, USA.
\end{abstract}

\begin{abstract}
Parkinson disease (PD) is characterized by dopaminergic neurodegeneration and intracellular inclusions of $\alpha$-synuclein amyloid fibers, which are stable and difficult to dissolve. Whether inclusions are neuroprotective or pathological remains controversial, because prefibrillar oligomers may be more toxic than amyloid inclusions. Thus, whether therapies should target inclusions, preamyloid oligomers, or both is a critically important issue. In yeast, the protein-remodeling factor Hsp104 cooperates with $\mathrm{Hsp} 70$ and $\mathrm{Hsp} 40$ to dissolve and reactivate aggregated proteins. Metazoans, however, have no Hsp104 ortholog. Here we introduced Hsp104 into a rat PD model. Remarkably, Hsp104 reduced formation of phosphorylated $\alpha$-synuclein inclusions and prevented nigrostriatal dopaminergic neurodegeneration induced by PD-linked $\alpha$-synuclein (A30P). An in vitro assay employing pure proteins revealed that Hsp104 prevented fibrillization of $\alpha$-synuclein and PD-linked variants (A30P, A53T, E46K). Hsp104 coupled ATP hydrolysis to the disassembly of preamyloid oligomers and amyloid fibers composed of $\alpha$-synuclein. Furthermore, the mammalian Hsp70 and Hsp40 chaperones, Hsc70 and Hdj2, enhanced $\alpha$-synuclein fiber disassembly by Hsp104. Hsp104 likely protects dopaminergic neurons by antagonizing toxic $\alpha$-synuclein assemblies and might have therapeutic potential for PD and other neurodegenerative amyloidoses.
\end{abstract}

\section{Introduction}

Abnormal protein aggregation in the brain characterizes several lethal neurodegenerative diseases (1), including Parkinson disease (PD). There are no cures for PD, the most common neurodegenerative movement disorder, which debilitates several million people worldwide (2). PD involves a progressive and selective elimination of dopaminergic neurons from the substantia nigra pars compacta, although neuropathology can extend into other brain regions (3). The signature lesions of PD are intracellular inclusions termed Lewy Bodies and Lewy neurites, which contain the small presynaptic protein, $\alpha$-synuclein ( $\alpha$-syn) (4). Although PD is primarily a sporadic disorder, mutations in $\alpha$-syn (e.g., A53T, A30P, E46K) and overexpression of the wild-type gene are linked with early-onset $\mathrm{PD}$ in rare familial forms of the disease (5).

The function of $\alpha$-syn is uncertain, but various studies connect $\alpha$-syn to synaptic vesicle pool regulation and dopamine release (5). Yet, how these potential functions might relate to PD is unclear. $\alpha$-syn is natively unstructured in isolation, but gains $\alpha$-helical structure upon association with phospholipid bilayers (6). Purified $\alpha$-syn forms amyloid fibers in vitro, which bind to the diagnostic dyes Thioflavin-T (ThT) and Congo red and possess the generic amyloid "cross- $\beta$ " conformation, in which the strands of the

Nonstandard abbreviations used: PD, Parkinson disease; $\alpha$-syn, $\alpha$-synuclein; TH, tyrosine hydroxylase; TH-IR, TH-immunoreactive; ThT, Thioflavin-T; YFP, yellow fluorescent protein.

Conflict of interest: The authors have declared that no conflict of interest exists. Citation for this article: J. Clin. Invest. 118:3087-3097 (2008). doi:10.1172/JCI35781. $\beta$-sheets run orthogonal to the fiber axis (7-9). Fibers assembled in vitro are very similar to $\alpha$-syn filaments isolated from synucleinopathy patients $(10,11)$. Once initiated, $\alpha$-syn amyloidogenesis can cascade out of control, because $\alpha$-syn fibers self-template by recruiting non-amyloid $\alpha$-syn conformers to fiber ends and converting them to the amyloid form (8). $\alpha$-syn fibers are exceptionally stable (e.g., protease and detergent resistant) and extraordinarily difficult to clear $(12,13)$.

Prior to fibrillization, $\alpha$-syn populates heterogeneous oligomeric states, which have not yet accessed the final cross- $\beta$ form of mature fibers. This ensemble of preamyloid oligomeric states comprises transient species that are likely "on-pathway" to fiber formation as well as "off-pathway" forms $(8,14,15)$. One of the transient oligomeric conformations populated by $\alpha$-syn is common to many amyloidogenic proteins regardless of their primary sequence and is recognized by a conformation-specific Ab (14). Preamyloid $\alpha$-syn oligomers may be more cytotoxic than fibers $(14,16)$, and sequestration of $\alpha$-syn into fiber inclusions at the expense of preamyloid oligomers might even be neuroprotective $(17,18)$. Despite intense investigation, how the process of $\alpha$-syn amyloidogenesis elicits the selective cell death that distinguishes PD and other synucleinopathies remains unclear.

PD-linked mutations in $\alpha$-syn increase its propensity to access misfolded forms. A53T and E46K fibrillize more rapidly than wildtype $\alpha$-syn, whereas A30P fibrillizes more slowly $(7,8,19)$. By contrast, A30P and A53T access preamyloid oligomers more rapidly than wild-type $\alpha$-syn, whereas E46K is less able to form these species $(8,20)$. Specific posttranslational modifications, such as phos- 
phorylation at serine 129 and nitration, also promote $\alpha$-syn fibrillization $(21,22)$. Phosphorylated and nitrated $\alpha$-syn selectively and abundantly accumulates in $\alpha$-synucleinopathy lesions in animal models and humans $(5,13,18,21)$. Together, this suggests that $\alpha$-syn misfolding contributes to familial and sporadic PD. Thus, inhibiting $\alpha$-syn misfolding and/or aggregation or promoting the clearance of $\alpha$-syn aggregates may constitute promising therapeutic strategies for PD and other synucleinopathies.

Protein misfolding is a problem as ancient as life itself, and so too are the solutions that synergize to antagonize it. Thus, sophisticated molecular chaperones recognize misfolded proteins and prevent their aggregation, protein-remodeling factors resolve protein aggregates, osmolytes function as chemical chaperones, and degradation systems eradicate misfolded proteins. Upregulation of protein quality control safeguards may provide important therapeutic avenues (23). Indeed, Hsp70 and Hsp40 chaperones associate with Lewy Bodies and Lewy neurites in PD and other synucleinopathies (24) as well as polyglutamine aggregates in several diseases $(25,26)$. Overexpression of Hsp70 and Hsp40 can suppress polyglutamine aggregation (25) or ameliorate toxicity associated with $\alpha$-syn aggregation (24). Yet, Hsp70 and Hsp40 have only very limited ability to resolve protein aggregates once they have formed (27). The ability to restore aggregated proteins to native structure and function would obviate the huge energetic cost of degrading and resynthesizing them. Further, this would simultaneously eliminate 3 malicious problems associated with protein aggregation that likely synergize in the etiology of various protein misfolding disorders: (a) the toxic gain of function of aggregated conformers; (b) the loss of function of the aggregated protein; and (c) the sequestration of other essential proteins that coprecipitate with the aggregated protein. However, whether mammals possess any activity that reverses protein aggregation and restores the functionality of aggregated proteins remains unclear.

By contrast, fungi, plants, and bacteria all express orthologs of Hsp104, a powerful protein-remodeling factor. All are hexameric $\mathrm{AAA}+$ (ATPases associated with diverse activities) proteins with 2 $\mathrm{AAA}+\mathrm{ATPase}$ domains per monomer $(28,29)$. Hsp104 synergizes with Hsp70 and Hsp40 to resolve protein aggregates and return proteins to normal enzymatic activity $(27,30)$. This increases cell survival after multifarious stresses by up to 10,000-fold $(31,32)$. Hsp104 also possesses an unusually powerful amyloid-remodeling activity and rapidly disassembles amyloid fibers composed of the yeast prion proteins Sup35 and Ure2 (29, 33-37). Moreover, Hsp104 eliminates Sup35 preamyloid oligomers that adopt a conformation shared by many amyloidogenic proteins, including $\alpha$-syn $(14,33,34)$. Critically, even transient overexpression of Hsp104 can purge yeast of Sup35 prions (38). Given these remarkable activities, which would appear beneficial to all cells, it is puzzling why Hsp104 has been lost from metazoan lineages. This issue remains moot and unaddressed. Nevertheless, Hsp104 can synergize with the mammalian Hsp70 chaperone system to promote protein disaggregation and stress tolerance $(39,40)$.

Disassembly of yeast prions by $\mathrm{Hsp} 104$ raises awareness that amyloids can be resolved by a protein-remodeling factor (28). Amyloids share a common cross- $\beta$ scaffold, where the $\beta$-sheet strands are aligned orthogonal to the fiber axis, irrespective of the primary sequence of the protein (41). Even though local steric details of different amyloids may vary enormously (41), this suggests that agents that antagonize amyloid fibers of one protein may also be active against amyloid fibers composed of another. Some preamyloid oligomers also share a common structure that is independent of primary sequence and distinct to that of fibers (14). Thus, can introduction of Hsp104 into metazoan systems prevent or reverse various amyloidoses? Answering this question will help clarify whether protein aggregation is protective or toxic in various disease settings.

The development of potential therapies for PD has been hampered by a paucity of animal models that recapitulate the selective loss of dopaminergic neurons. Here we employ a rat PD model based on the lentiviral-mediated expression of human $\alpha$-syn A30P in the substantia nigra, which successfully recreates the progressive and selective degeneration of dopaminergic neurons and formation of phosphorylated $\alpha$-syn inclusions that characterize PD $(18,42)$. We first evaluated whether Hsp104 affects $\alpha$-syn toxicity and aggregation in this model. Because Hsp104 does not have general anti-apoptotic effects (e.g., in response to staurosporine or hydrogen peroxide) when expressed in mammalian cells (43), any reductions in toxicity will likely reflect direct effects on $\alpha$-syn misfolding. We then employed pure proteins to delineate how Hsp104 modulates $\alpha$-syn aggregation. Our studies highlight the therapeutic utility of Hsp104 for neurodegenerative disease and provide new insights into the controversial issues of how protein aggregation and inclusion formation contribute to PD pathogenesis and other diseases.

\section{Results}

Hsp104 reduces $\alpha$-syn-induced toxicity. Overexpression of mutated human $\alpha$-syn with viral vectors induces a progressive loss of nigral dopamine neurons in rodents and nonhuman primates (42, 44-46). To test whether Hsp104 modulates $\alpha$-syn aggregation and $\alpha$-syninduced degeneration of dopamine neurons, we simultaneously overexpressed Hsp104 and A30P $\alpha$-syn in the brain of rats. Viral suspensions containing lentiviral vectors coding either for A30P human $\alpha$-syn and Hsp104 (lenti-A30P/lenti-Hsp104; see Methods) or for A30P human $\alpha$-syn and yellow fluorescent protein (lentiA30P/lenti-YFP; see Methods) were directly injected in the substantia nigra of rats. Brain slices from the substantia nigra were then stained for the dopaminergic marker tyrosine hydroxylase (TH), the rate-limiting enzyme in dopamine synthesis.

Animals injected with lentiviral vectors coding for A30P $\alpha$-syn showed a $33 \%$ loss of TH-immunoreactive (TH-IR) neurons in the substantia nigra at 6 weeks after injection (42). Importantly, viral expression of 2 reporter proteins (YFP/GFP) does not induce any damage to the nigrostriatal pathway (18). In contrast, injection of lenti-A30P/lenti-YFP in the right side of the rat substantia nigra induced a marked loss of TH-IR cells compared with the noninjected side (Figure 1A), similar to the expression of A30P $\alpha$-syn alone. Coexpression of Hsp104 rescued TH-IR neurons from A30P $\alpha$-syn-induced toxicity (Figure 1A). Quantitation of neuronal loss was performed throughout the whole substantia nigra (Figure 1B). The contralateral noninjected side was used as an internal control. Animals expressing A30P/YFP revealed a 31.4\% loss of TH-IR cells relative to the contralateral side. Expression of Hsp104 resulted in a significant reduction in cell loss $(12.6 \% ; P<0.05 ; n=7)$. Confocal analysis of animals expressing Hsp104/A30P revealed that surviving dopamine neurons still expressed abundant levels of human $\alpha$-syn (Figure 1C).

Hsp104 prevents A30P $\alpha$-syn-induced neurodegeneration. Nigral dopaminergic neurons project their nerve terminals directly to the striatum. Lentiviral-mediated expression of A30P $\alpha$-syn in the substantia nigra of rats induces a significant loss of striatal nerve ter- 


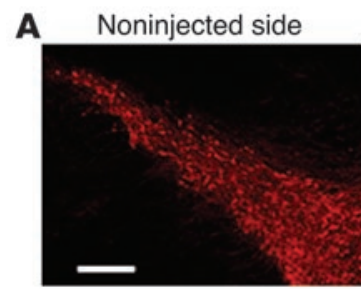

Noninjected side

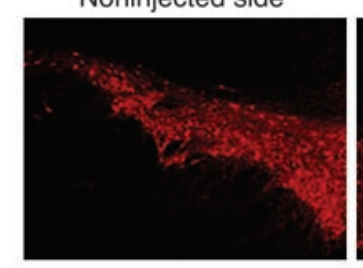

C
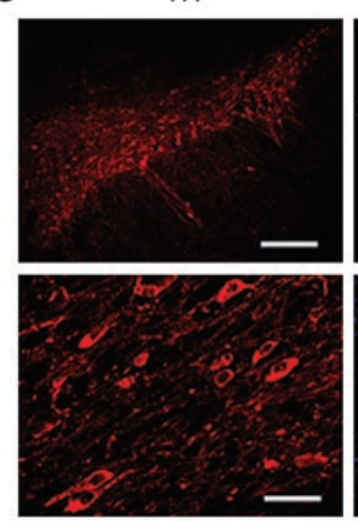

A30P/YFP

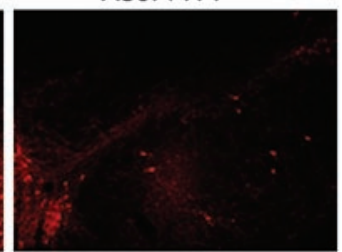

A30P/Hsp104

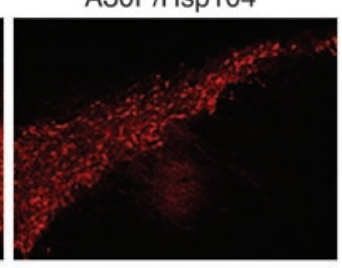

A30P $\alpha$-syn
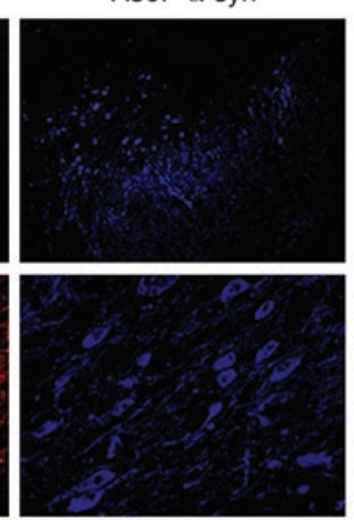

B

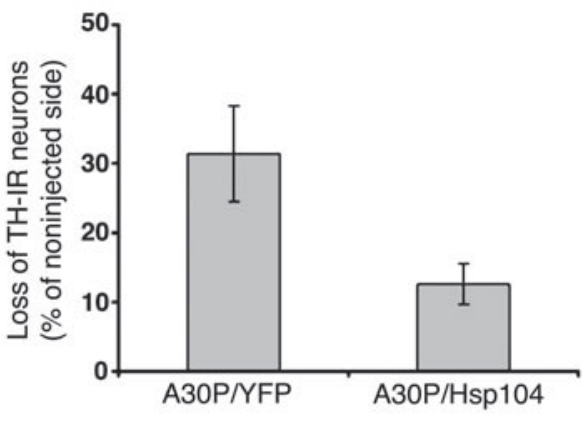

Hsp104
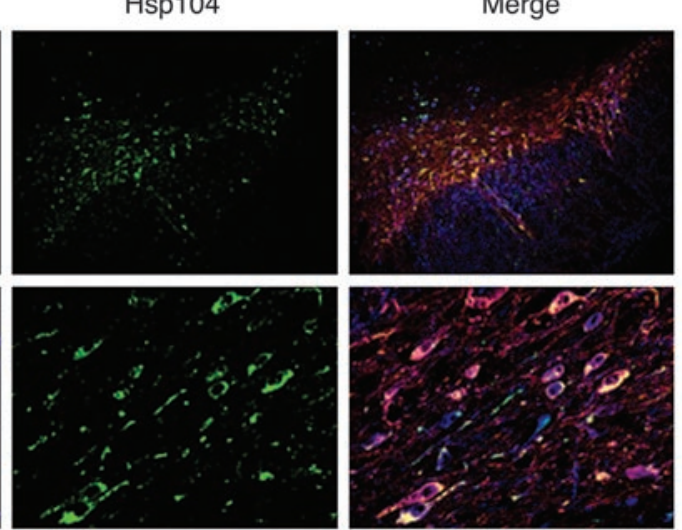

Figure 1

Hsp104 reduces dopaminergic cell loss in the substantia nigra of rats expressing human $\alpha$-syn A30P. (A) Staining for TH at 6 weeks in the substantia nigra of rats injected with either lenti-A30P/lenti-YFP or lenti-A30P/lenti-Hsp104. (B) Quantitation of TH-IR nigral neurons at 6 weeks relative to the contralateral side in rats unilaterally injected with the different lentiviral constructs. Values represent mean $\pm \mathrm{SEM} ; n=7$ animals for both A30P/YFP and A30P/Hsp104 groups; $P<0.05$. (C) Confocal imaging of triple labeling for TH (red), A30P human $\alpha$-syn (blue), and Hsp104 (green) in the rat substantia nigra injected with lenti-A30P/lenti-Hsp104. Higher magnification (bottom row) reveals numerous TH neurons positive for Hsp104 and A30P human $\alpha$-syn at 6 weeks after injection. Scale bar: $350 \mu \mathrm{m}$ (A and C, top row); $60 \mu \mathrm{m}$ (C, bottom row).

minals (42). To determine whether the protective effect of Hsp104 on dopaminergic cells is accompanied by reductions in the loss of nerve terminals in the striatum, TH staining was performed on striatal brain slices from animals expressing either A30P/YFP or A30P/Hsp104 (Figure 2A).

Animals expressing A30P/YFP showed a decrease in the TH marker in the ipsilateral side (Figure 2A). Nigral expression of Hsp104 reduced the dopaminergic nerve terminal loss induced by the accumulation of A30P $\alpha$-syn (Figure 2A). Quantitation of TH-IR fiber density was performed throughout the striatum. Consistent with the neuroprotective effect of Hsp104 at the cellular level, expression of Hsp104 significantly decreased the nerve terminal loss from $21.6 \%$ (A30P/YFP) to 7\% (A30P/Hsp104) $(P<0.05 ; n=7)$ (Figure 2B).

Next, we used silver staining as a marker for degenerating neurons in animals expressing A30P/YFP or A30P/Hsp104 (42, 47, 48). No silver staining was observed in the noninjected substantia nigra (Figure 3, A and D). In contrast, scattered neurons containing silver-positive dark structures were observed in animals injected with lenti-A30P/lenti-YFP, consistent with $\alpha$-syn-induced degeneration $(18,42)$ (Figure 3B). Higher magnifications revealed that animals expressing A30P/YFP abundantly accumulated granular deposits in both cell bodies and axons at the substantia nigra level (Figure 3, E and G) (42). Clear neuritic pathology was also observed (Figure $3 \mathrm{G})$. In stark contrast, coexpression of Hsp104 greatly reduced the appearance of silver-positive degenerating neurons and granular silver deposits (Figure 3, C and F), indicating that Hsp104 antagonizes A30P $\alpha$-syn-induced neurodegeneration. Only a few sparse silver-positive neurons were still observed in the A30P/Hsp104 group. Although these observations were consistently observed in animals expressing Hsp104, the high variability in the signal/noise ratio observed with silver staining among sections, even within the same animal, prevents quantification.

Hsp104 reduces the formation of phosphorylated inclusions. To understand the mechanism by which Hsp104 prevents $\alpha$-syn-induced neurodegeneration, we investigated how Hsp104 affects the $\alpha$-syn aggregation in vivo. Two different Abs were used to detect $\alpha$-syn in animals expressing either A30P/YFP or A30P/Hsp104 (Figure 4). The Ab RG syn recognizes both rat and human $\alpha$-syn by western blot (42). However, this Ab only detects overexpression of $\alpha$-syn and not endogenous levels of this protein in the rat brain (42). 
A
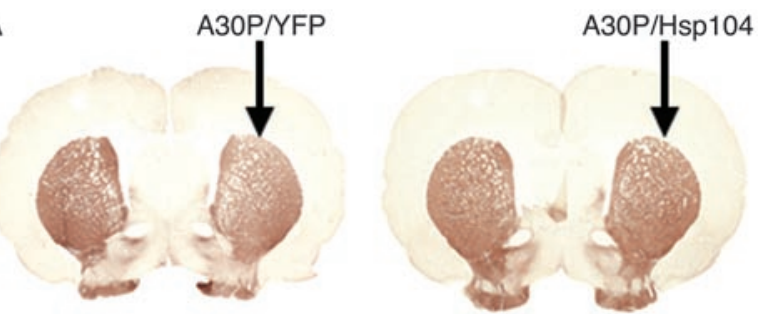

B

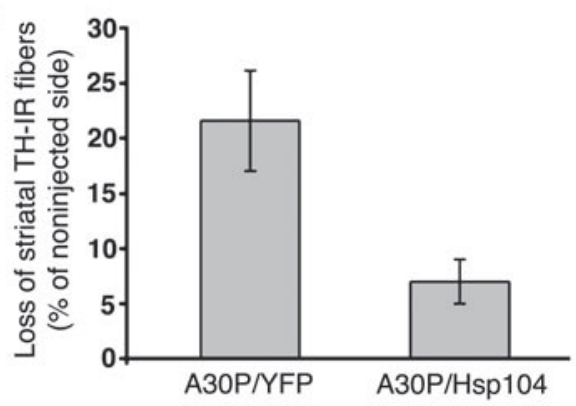

Stainings with LB509, an Ab that is specific for human $\alpha$-syn, were also performed (Figure 4, D-I). A strong accumulation of human $\alpha$-syn in both the perikarya and neurites is observed in the substantia nigra of animals expressing either A30P/YFP (Figure 4, B and E) or A30P/Hsp104 (Figure 4, C and F) as compared with noninjected animals (Figure 4, A, D, and G). Examination at higher magnification illustrates the difficulty in discriminating between $\alpha$-syn aggregates and subcellular accumulation of this protein (Figure 4, $\mathrm{H}$ and I). High levels of soluble $\alpha$-syn may mask the appearance of aggregates and render quantification very difficult. However, in some neurons, dense puncta were frequently observed in neurites, and these were less evident in animals expressing Hsp104. Furthermore, a more dense coloration inside the perikarya of

\section{Figure 2}

Hsp104 reduces $\alpha$-syn-induced dopaminergic fiber loss in the striatum of rats. (A) Striatal sections stained for TH from rats after intranigral injections of either lenti-A30P/lenti-YFP or lenti-A30P/lenti-Hsp104 (arrows indicate the injected sides). Original magnification, $\times 3$. (B) Quantitation of the loss of TH fibers at 6 weeks, relative to the contralateral side in rats unilaterally injected with the different lentiviral vectors. Values represent mean \pm SEM; $n=7$ animals per group; $P<0.05$.

$\alpha$-syn-positive neurons indicates the presence of $\alpha$-syn aggregates (Figure 4, H and I). Hsp104 significantly reduces the percentage of $\alpha$-syn-positive neurons harboring dense structures in cell bodies or axons $(54.8 \% \pm 5.5 \%$ and $30.8 \% \pm 4.4 \%$ for A30P/YFP and A30P/Hsp104, respectively; mean $\pm \mathrm{SEM} ; P<0.05 ; n=7$ ). Interestingly, in animals expressing Hsp104, we detected a more diffuse and homogenous $\alpha$-syn localization along the neuropil, indicating that Hsp104 antagonizes the dense structures or aggregates and helps maintain soluble forms of $\alpha$-syn. These data suggest that Hsp104 may antagonize $\alpha$-syn aggregation in vivo.

To evaluate more clearly, whether Hsp104 affected $\alpha$-syn aggregation in vivo, we assessed phosphorylated $\alpha$-syn inclusions. $\alpha$-syn phosphorylated predominantly at serine 129 selectively and abundantly accumulates in both Lewy bodies of PD patients and inclusions of $\alpha$-syn animal models $(13,18,21)$. Therefore, we quantified the number of phosphorylated inclusions with the Pser129 Ab specific for phosphorylated $\alpha$-syn at serine $129(18,21)$ (Figure 4, J-M). As described previously (18), expression of A30P $\alpha$-syn leads to the formation of phosphorylated inclusions (Figure $4 \mathrm{~K}$ ) as compared with noninjected animals (Figure 4J). Strikingly, coexpression of Hsp104 with A30P $\alpha$-syn resulted in a 57\% reduction in the number of neurons containing phosphorylated inclusions (Figure 4, L and $\mathrm{M}$ ), indicating that $\mathrm{Hsp} 104$ may protect dopaminergic cells by decreasing the numbers of phosphorylated $\alpha$-syn aggregates.

Hsp104 inhibits $\alpha$-syn amyloidogenesis. From our in vivo experiments, it is difficult to distinguish whether Hsp104 prevents aggregation

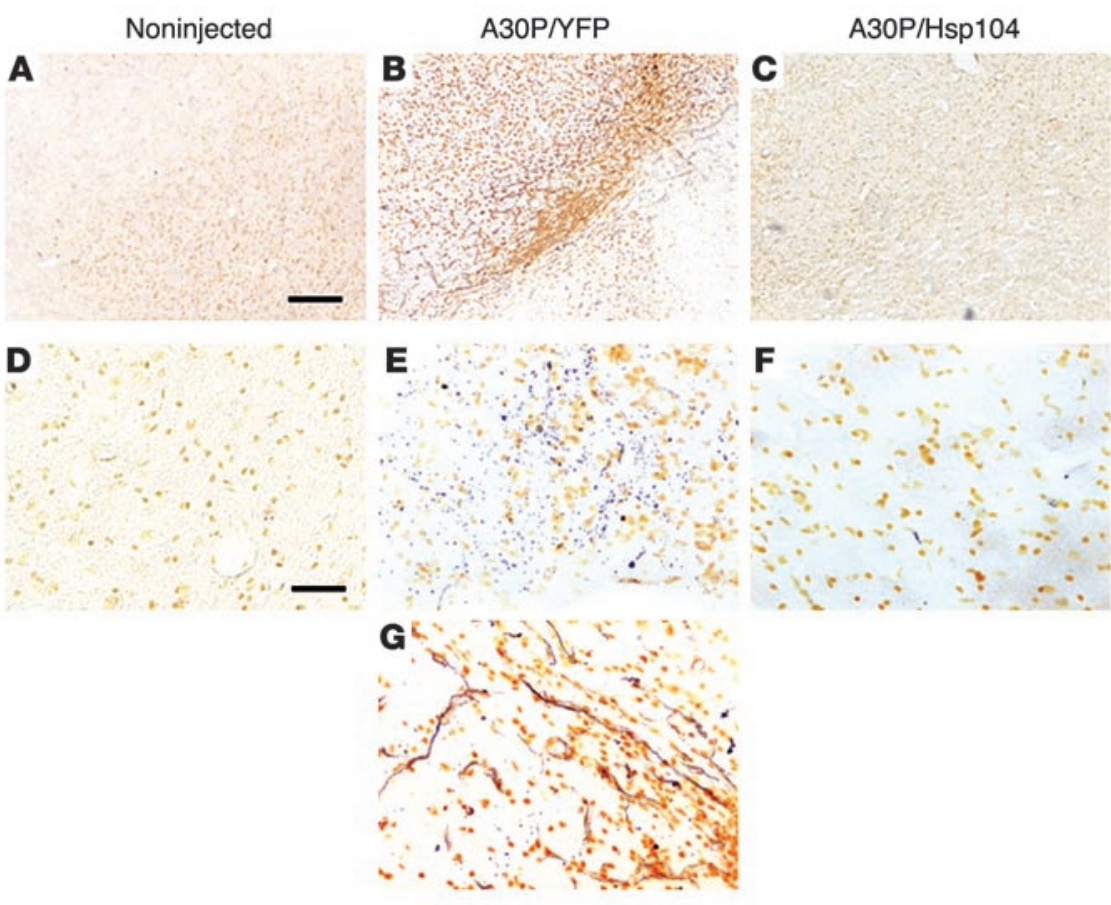

\section{Figure 3}

Hsp104 prevents A30P $\alpha$-syn-induced neurodegeneration. (A-G) Degenerating nigral neurons were detected by silver staining. ( $A$ and $\mathbf{D})$ Noninjected sides did not show any specific silver staining. (D-G) Higher magnification reveals numerous silver-positive dark structures in the substantia nigra of animals expressing A30P/ YFP (E). (G) Abundant neuritic pathology clearly showed the presence of degenerating neurites. (C and F) Coexpression of Hsp104 with A30P $\alpha$-syn prevents the appearance of silver-positive degenerating neurons. Scale bar: $300 \mu \mathrm{m}$ (A-C); $100 \mu \mathrm{m}$ (D-G). 

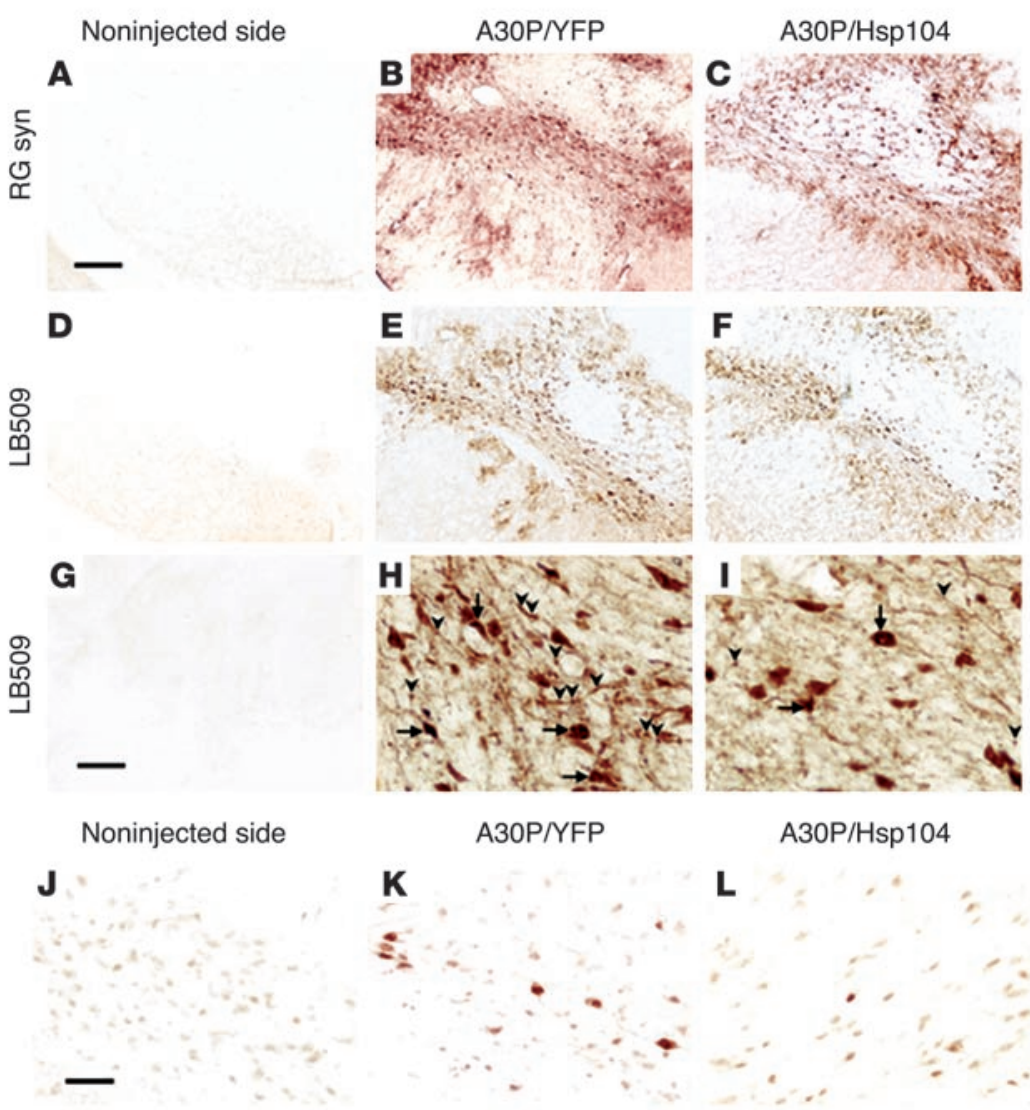

A30P/YFP

\begin{abstract}
A30P/Hsp104
\end{abstract}

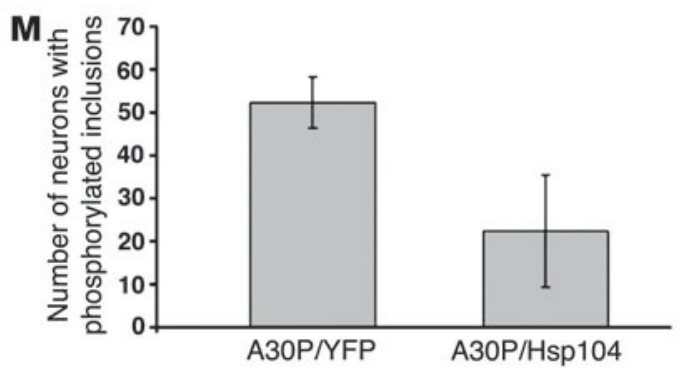

of $\alpha$-syn or resolubilizes $\alpha$-syn after it has aggregated. Therefore, we determined how Hsp104 affects $\alpha$-syn amyloidogenesis in vitro using pure proteins. In vitro, purified $\alpha$-syn assembles into fibers, which are very similar to $\alpha$-syn filaments isolated from synucleinopathy patients $(9,10)$. $\alpha$-syn assembled into amyloid fibers after a lag of approximately 5 hours of incubation, and assembly was virtually complete after approximately 24 hours as assessed by ThT fluorescence (a diagnostic amyloid dye) (Figure 5A) and sedimentation analysis (Figure 5B). When Hsp104 was added at substoichiometric levels ( $\alpha$-syn monomers/Hsp104 hexamers, 80:0.2 $\mu \mathrm{M})$ fibrillization was retarded (Figure 5, A and B). Remarkably, higher Hsp104 concentrations ( $\alpha$-syn monomers/Hsp104 hexamers, 80:0.8 $\mu \mathrm{M}$ or 80:1.6 $\mu \mathrm{M}$ ) allowed very little fibrillization after 48 hours (Figure 5, A and B). EM confirmed that Hsp104 inhibited $\alpha$-syn fibrillization (Figure 5C). Amorphous material accumulated in the presence of Hsp104 (Figure 5C). Inhibition of $\alpha$-syn fibrillization by Hsp 104 was stable until approximately 72 hours (data not shown). After 96 hours, Hsp104 began to lose activity and some $\alpha$-syn fibrillization was able to occur (Figure 5D). However, if reac-

\section{Figure 4}

Hsp104 reduces the number of phosphorylated $\alpha$-syn inclusions. (A-C) Robust expression of human $\alpha$-syn was detected with both RG syn and (D-I) the human specific LB509 Abs. (G-I) Higher magnification revealed the accumulation and aggregation of human $\alpha$-syn in both the cell bodies (arrows) and neurites (arrowheads). (H and I) Note that there are fewer dense puncta in neurites in the A30P/Hsp104 condition. (J) Sections of the substantia nigra from the noninjected side and (K) from rats expressing A30P/YFP or (L) A30P/Hsp104 were immunostained with Ab specific for phosphorylated Ser 129 of $\alpha$-syn. The substantia nigra of animals overexpressing either A30P/YFP or A30P/ Hsp104 reveals the presence of hyperphosphorylated inclusions reminiscent of Lewy bodies. Scale bar: $300 \mu \mathrm{m}$ (A-F); $40 \mu \mathrm{m}$ (G-I); $50 \mu \mathrm{m}$ (J-L). (M) Quantitation of neurons containing Pser129-positive aggregates in the substantia nigra of rats expressing A30P/ YFP or A30P/Hsp104. Values represent mean \pm SEM; $n=6$ animals per group; $P<0.05$.

tions were supplemented with additional Hsp104 at 72 hours, the inhibition of $\alpha$-syn fibrillization was maintained (Figure 5D). Thus, the inhibition $\alpha$-syn fibrillization is stable, provided there is a renewable source of active Hsp104.

Hsp104 afforded little inhibition of $\alpha$-syn fibrillization in the absence of ATP and inhibition was reduced by the presence of the nonhydrolyzable ATP analogue, AMP-PNP (Figure 5A). We also employed Hsp104 carrying mutations in the highly conserved Walker A motifs of both AAA+ ATPase domains, Hsp104 ${ }^{\mathrm{K} 218 T: K 620 T}$, which is defective in ATP binding and hydrolysis at both sites (49). The mutant failed to inhibit $\alpha$-syn fibrillization (Figure 5A). Thus, maximal inhibition of $\alpha$-syn fibrillization requires ATP binding and hydrolysis by Hsp104.

Next, we tested whether Hsp104 could inhibit the fibrillization of PD-linked $\alpha$-syn variants, including A30P, A53T, and E46K. A53T and E46K assemble into amyloid fibers more rapidly than wild-type $\alpha$-syn, whereas A30P accesses preamyloid oligomers more rapidly than wild type but takes longer to form fibers $(7,19)$. Hsp104 inhibited A53T fibrillization at early times, but this inhibition was overcome by 48 hours of incubation (Figure 5E). Stable inhibition of A53T over the 48-hour time frame required higher concentrations of Hsp104 (Figure 5E), perhaps because A53T assembles more rapidly than any of the other $\alpha$-syn variants. By contrast, Hsp104 inhibited fibrillization by A30P and E46K just as well as wild-type $\alpha$-syn (Figure 5E). Thus, Hsp104 potently inhibits the assembly of the spectrum of PD-linked $\alpha$-syn mutants.

In synucleinopathy patients, $\alpha$-syn is phosphorylated on serine 129 , which may stimulate $\alpha$-syn fibrillization (21). We found that Hsp104 inhibits fibrillization of both $\alpha$-syn S129A, which cannot be phosphorylated at position 129, and S129E, which may mimic $\alpha$-syn phosphorylated at S129 (Figure 5E). Therefore, the reduction in phosphorylated $\mathrm{A} 30 \mathrm{P} \alpha$-syn inclusions observed in vivo is likely due, at least in part, to the inhibition of their assembly by Hsp104.

Hsp104 remodels $\alpha$-syn A30P preamyloid oligomers. Preamyloid oligomers may be the more cytotoxic species in many neurodegen- 

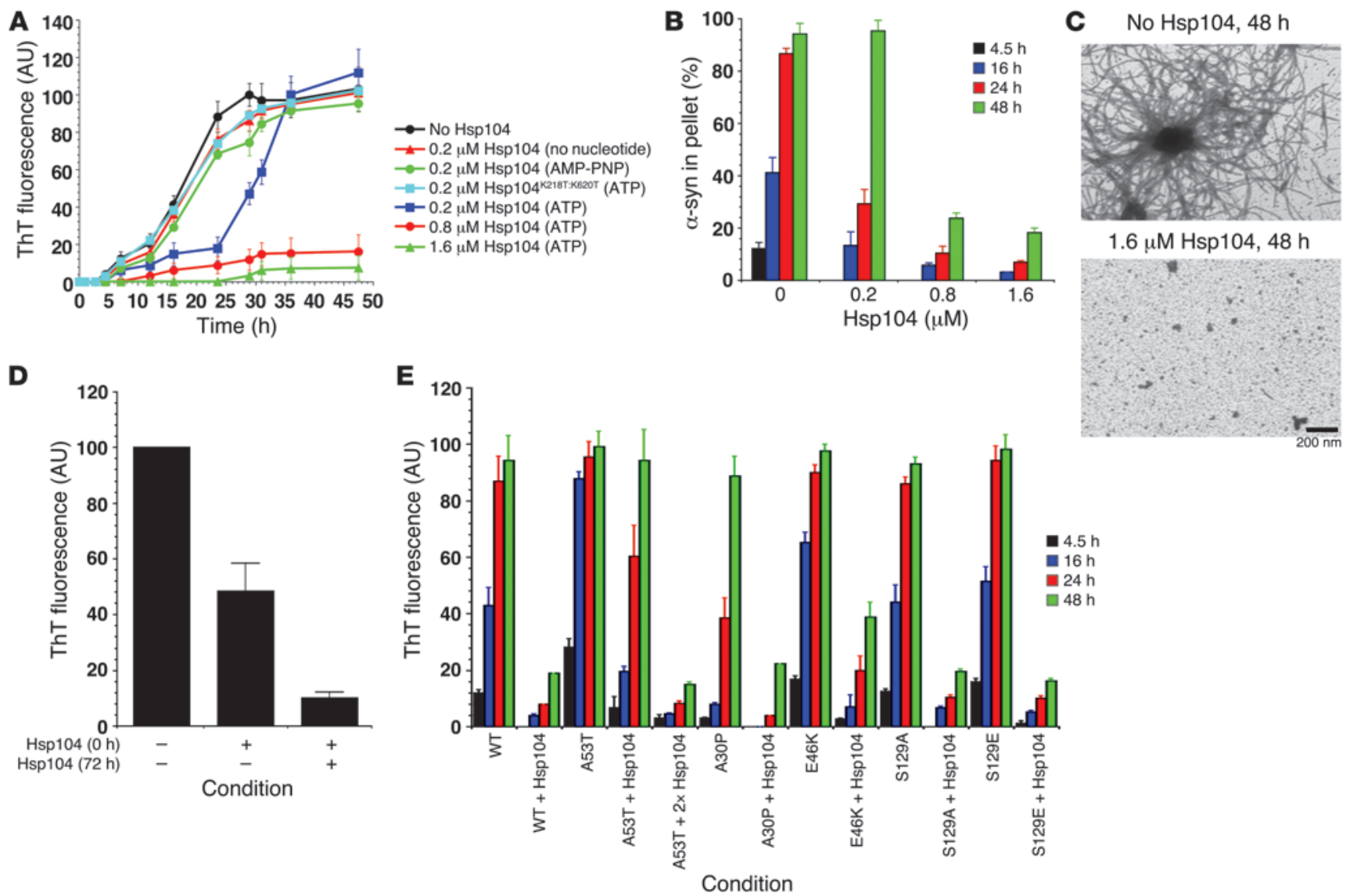

Figure 5

Hsp104 inhibits $\alpha$-syn fibrillization. (A and B) Kinetics of rotated $(80 \mathrm{rpm}) \alpha$-syn $(80 \mu \mathrm{M})$ fibrillization at $37^{\circ} \mathrm{C}$ without or with either $\mathrm{Hsp} 104$ $(0.2-1.6 \mu \mathrm{M})$ plus ATP and regeneration system $(20 \mathrm{mM}$ creatine phosphate and $0.1 \mathrm{mg} / \mathrm{ml}$ creatine kinase), Hsp104 (0.2 $\mu \mathrm{M})$ with no nucleotide, Hsp104 (0.2 $\mu \mathrm{M})$ plus nonhydrolyzable ATP analogue (AMP-PNP), or Hsp104K218T:K620T (0.2 $\mu \mathrm{M})$ plus ATP and regeneration system. Fibrillization was measured by ThT fluorescence $(\mathbf{A})$ or sedimentation analysis (B). Values represent mean $\pm \mathrm{SD} ; n=3$. (C) EM of $\alpha$-syn (80 $\mu \mathrm{M})$ fibrillization at $37^{\circ} \mathrm{C}$ for 48 hours without or with Hsp104 (1.6 $\left.\mu \mathrm{M}\right)$ plus ATP and regeneration system. Scale bar: $200 \mathrm{~nm}$. (D) $\alpha$-syn (80 $\left.\mu \mathrm{M}\right)$ was incubated for 96 hours with rotation at $37^{\circ} \mathrm{C}$ in the presence or absence of Hsp104 $(1.6 \mu \mathrm{M})$ plus ATP and regeneration system. After 72 hours, reactions were either supplemented with buffer or fresh Hsp104 (1.6 $\mu \mathrm{M})$. Fibrillization was measured by ThT fluorescence. Values represent mean \pm SD; $n=3$. (E) Fibrillization kinetics of wild-type, A53T, A30P, E46K, S129A, and S129E $\alpha$-syn ( $80 \mu \mathrm{M})$ in the presence or absence of Hsp104 (2 $\mu \mathrm{M})$ plus ATP and regeneration system. Another reaction contained A53T (80 $\mu \mathrm{M})$ plus Hsp104 $(4 \mu \mathrm{M})$ with ATP and regeneration system. Reactions were rotated $(80 \mathrm{rpm})$ at $37^{\circ} \mathrm{C}$. Fibrillization was measured by ThT fluorescence. Values represent mean $\pm \mathrm{SD} ; n=4$.

erative amyloidoses, including synucleinopathies (14, 50). Further, they are likely important intermediates in the fibrillization process $(8,15,33,34)$. Thus, we determined if Hsp104 could remodel preformed A30P preamyloid oligomers. A30P preamyloid oligomers were formed and purified away from monomers by gel filtration (15). Purified A30P preamyloid oligomers are stable for long periods ( 10 days) and do not dissociate into monomers or dimers (15). However, to ensure our starting material was $100 \%$ oligomeric, purified A30P preamyloid oligomers were treated immediately with Hsp104 or Hsp104 ${ }^{\mathrm{K} 218 \mathrm{~T}: \mathrm{K} 620 \mathrm{~T}}$. Hsp104 ${ }^{\mathrm{K} 218 \mathrm{~T}: \mathrm{K} 620 \mathrm{~T}}$ was unable to remodel preamyloid A30P oligomers as determined by anti-oligomer immunoreactivity, EM, and retention by a $100-\mathrm{kDa}$ filter (Figure 6). By contrast, Hsp104 reduced anti-oligomer immunoreactivity (Figure 6A), and EM revealed that Hsp104 disassembled A30P preamyloid oligomers (Figure 6B). A30P was now able traverse a $100-\mathrm{kDa}$ filter (Figure 6, C and D). Thus, Hsp104 eradicates $\alpha$-syn A30P preamyloid oligomers, which are potentially the most toxic species that arise during A30P amyloidogenesis (14).
Hsp104 remodels $\alpha$-syn fibers. Finally, we tested whether Hsp104 remodeled fibers formed by wild-type $\alpha$-syn as well as PD-linked mutants A30P, A53T, and E46K and the serine 129 mutants S129A and S129E. Remarkably, Hsp104 disassembled fibers composed of wild-type $\alpha$-syn, A53T, A30P, and S129A as revealed by ThT fluorescence (Figure 7A) and turbidity (Figure 7B). Of these, A30P was the most susceptible to disassembly by Hsp104 (Figure 7, A-C). This required ATP hydrolysis by Hsp104 and was not observed with Hsp104 ${ }^{\mathrm{K} 218 \mathrm{~T}: \mathrm{K} 620 \mathrm{~T}}$ or in the presence of AMP-PNP (Figure 7, A and B). Intriguingly, S129E fibers were more resistant to disassembly by Hsp104, and E46K fibers were refractory to Hsp104. In sum, these data suggest that Hsp104 disassembles fibers composed of wild-type $\alpha$-syn and some PD-linked $\alpha$-syn variants.

Hsp104 combines with mammalian Hsp70 and Hsp40 chaperones to promote reactivation of denatured luciferase aggregates $(27,40)$. Thus, we tested whether mammalian Hsp70 and Hsp40 chaperones could assist Hsp104 in disassembling $\alpha$-syn fibers. In contrast to Hsp104 alone, Hsp70 and Hsc70 alone or in combina- 

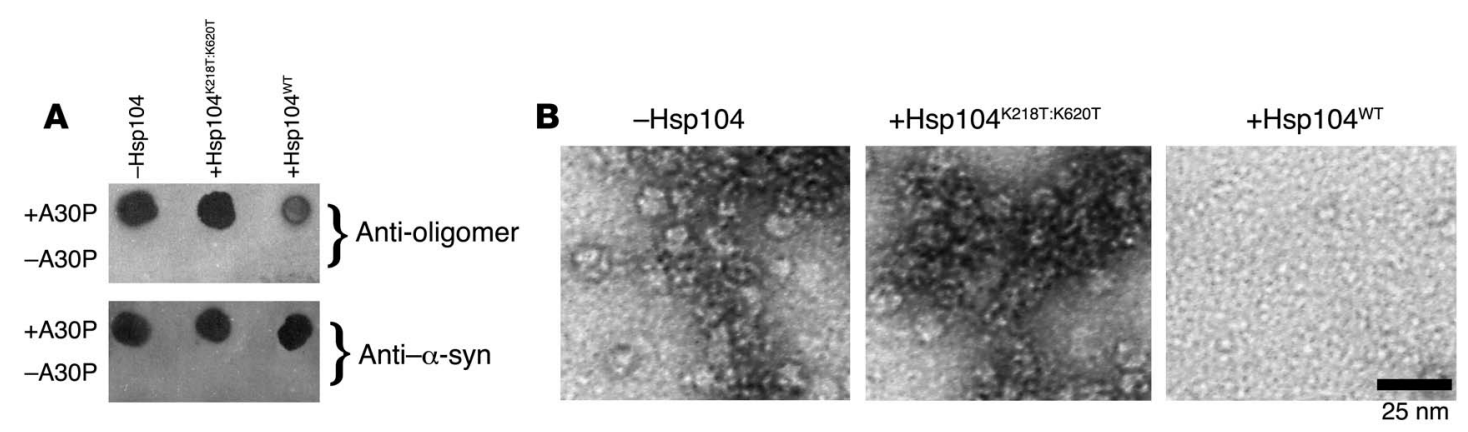

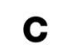

C

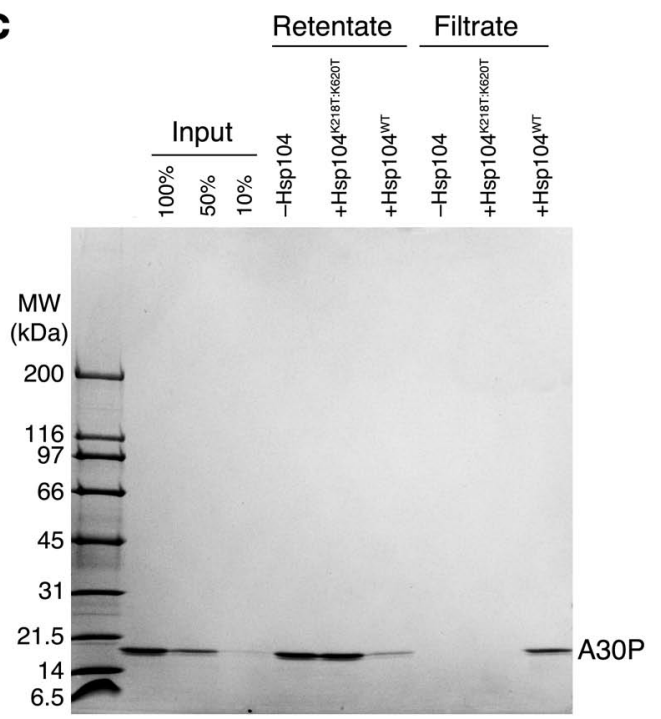

D

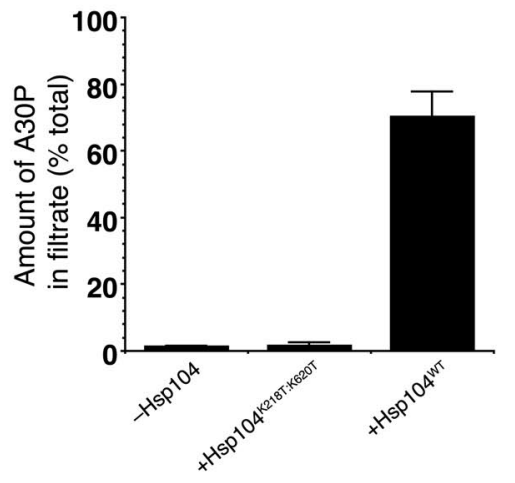

Figure 6

Hsp104 remodels $\alpha$-syn A30P preamyloid oligomers. (A-D) Purified $\alpha$-syn A30P preamyloid oligomers $(0.5 \mu \mathrm{M})$ were incubated without or with Hsp104 or Hsp104К218T:К620T $(10 \mu \mathrm{M})$ plus ATP and regeneration system for 1 hour at $37^{\circ} \mathrm{C}$. Reactions were spotted on nitrocellulose and probed with anti-oligomer Ab or anti- $\alpha$-syn Ab (A). (B) Alternatively, reactions were processed for EM (scale bar: $25 \mathrm{~nm}$ ) or (C) depleted of Hsp104 and passed through a 100-kDa molecular weight filter. (C and D) Retentate and filtrate fractions were collected and analyzed by SDS-PAGE, and the amount of $\mathrm{A3OP}$ in the filtrate was determined by densitometry. Values represent mean $\pm \mathrm{SD} ; n=4$ (D).

tion with either Hdj1 or Hdj2 were unable to disassemble $\alpha$-syn fibers over the time frame of the assay (Figure 7, D and E). Hsp104 combined with Hsc70 and Hdj2 to promote more $\alpha$-syn fiber disassembly than Hsp104 alone as determined by ThT fluorescence (Figure 7D) and sedimentation analysis (Figure 7E). To a lesser extent, Hsp104, Hsp70, and Hdj2 promoted more $\alpha$-syn fiber disassembly than Hsp104 alone (Figure 7, D and E), while other combinations were equally (Hsp104, Hsp70, and Hdj1) or slightly less (Hsp104, Hsc70, and Hdj1) effective than Hsp104 alone (Figure 7, $\mathrm{D}$ and $\mathrm{E})$. Overall, these data demonstrate that Hsp104 antagonizes various $\alpha$-syn conformations populated during amyloidogenesis, and that the mammalian Hsp70 chaperone system can assist Hsp104 in disassembling $\alpha$-syn fibers.

\section{Discussion}

Here we show for what we believe to be the first time that augmentation of the mammalian protein quality control system with a protein-remodeling factor not ordinarily found in metazoa, Hsp104, dramatically reduces dopaminergic neurodegeneration and phosphorylated $\alpha$-syn inclusion formation in a rat lentiviral model of PD. To help understand these events, we employed pure proteins to analyze how Hsp104 affects $\alpha$-syn amyloidogenesis. Importantly, Hsp104 directly inhibits the fibrillization of $\alpha$-syn as well as the PD-linked $\alpha$-syn mutants A53T, A30P, and E46K and the serine 129 phosphorylation mutants S129A and S129E. Hsp 104 inhibited $\alpha$-syn fibrillization even when $\alpha$-syn was 400-fold more abundant than Hsp104. This suggests that Hsp104 specifically antagonizes a rare or transient $\alpha$-syn conformer, perhaps a specific oligomeric species, which nucleates $\alpha$-syn fibrillization. Indeed, Hsp104 disassembled purified A30P preamyloid oligomers that adopted a toxic conformation common to many amyloidogenic proteins (14). Such $\alpha$-syn preamyloid oligomers are toxic to human neuroblastoma SH-SY5Y cells (14), suggesting that Hsp104 eliminates toxic $\alpha$-syn conformers. Crucially, Hsp104 disassembled preformed $\alpha$-syn fibers. Specific mammalian Hsp70 and Hsp40 chaperones, most notably Hsc70 and Hdj2, increased $\alpha$-syn fiber disassembly by Hsp104. This is to our knowledge the first demonstration of effective disassembly of both $\alpha$-syn preamyloid oligomers and amyloid fibers (which are particularly stable structures) by any protein. These various $\alpha$-syn-remodeling activities required ATP binding and hydrolysis by Hsp104 and explain how Hsp104 might reduce dopaminergic 

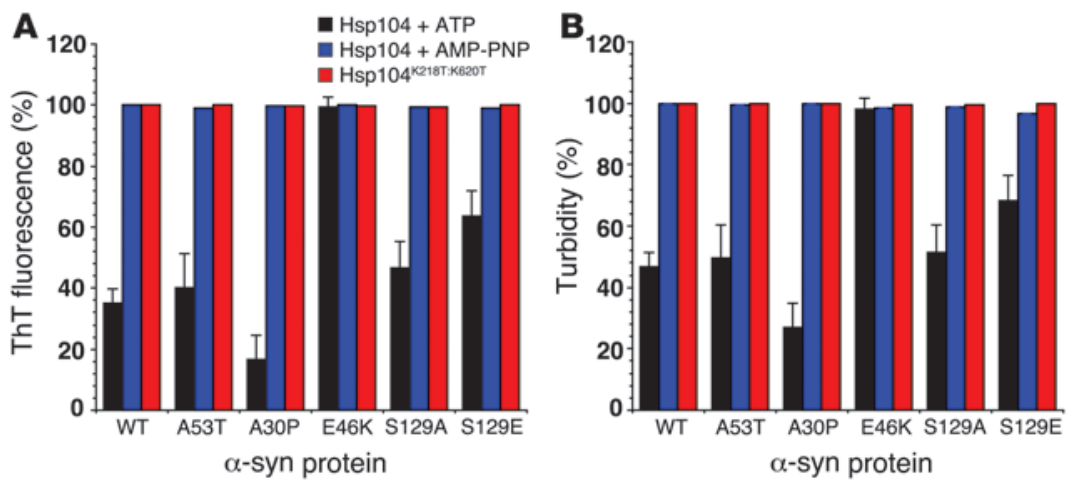

\section{Figure 7}

Hsp104 remodels $\alpha$-syn fibers. (A and B) Fibers composed of wild-type, A53T, A30P, E46K, S129A, or S129E $\alpha$-syn (0.5 mM monomer) were incubated with Hsp104 ${ }^{\mathrm{K} 218 \mathrm{~T}: \mathrm{K} 620 \mathrm{~T}}$, Hsp104 $(10 \mu \mathrm{M})$ plus ATP and regeneration system, or AMP-PNP system for 1 hour at $37^{\circ} \mathrm{C}$. Fiber integrity was determined by ThT fluorescence $(\mathbf{A})$ or turbidity (B). For each fiber, $100 \%$ assembly reflects untreated fibers. Values represent mean $\pm \mathrm{SD}$; $n=3$. (C) EM of A30P fibers incubated without or with Hsp104 with ATP and regeneration system as in A. Scale bar: $0.5 \mu \mathrm{m}$. (D and E) Fibers composed of wild-type $\alpha$-syn ( $0.5 \mu \mathrm{M}$ monomer) were incubated for 1 hour at $37^{\circ} \mathrm{C}$ without or with the indicated combinations of Hsp104 $(10 \mu \mathrm{M})$, Hsp70 $(10 \mu \mathrm{M}), \operatorname{Hsc70}(10 \mu \mathrm{M}), \operatorname{Hdj} 1(10 \mu \mathrm{M})$, or Hdj2 $(10 \mu \mathrm{M})$ plus ATP and regeneration system. Fiber integrity was determined by ThT fluorescence (D) or sedimentation analysis (E). Values represent mean $\pm \mathrm{SD} ; n=3$.

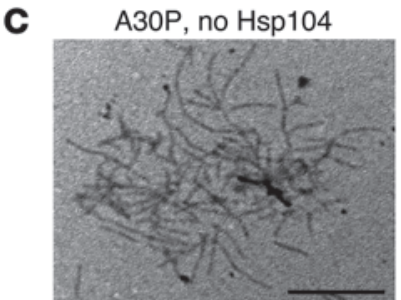

D

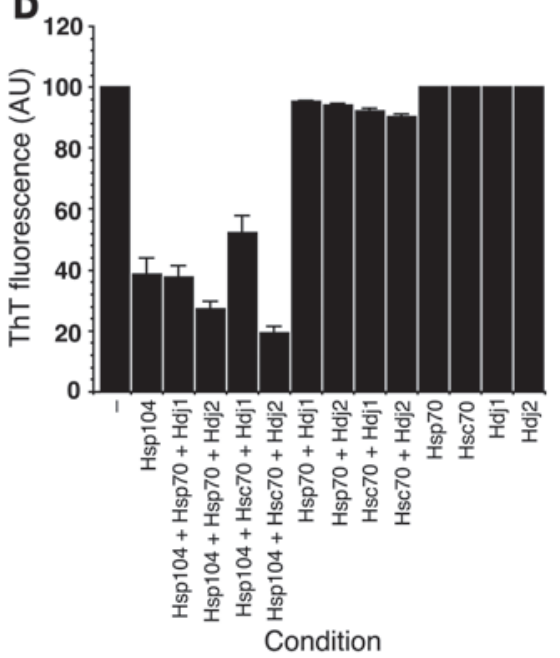

$\mathrm{A} 30 \mathrm{P}+\mathrm{Hsp} 104$

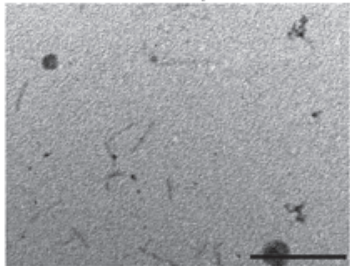

E

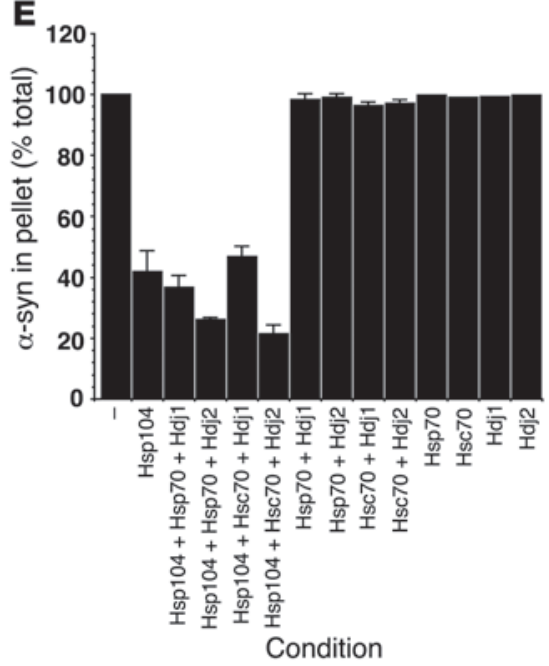

neurodegeneration and phosphorylated $\alpha$-syn inclusion formation in the arena of the rat brain.

Two previous studies claim to provide evidence that Hsp104 can dissociate $\alpha$-syn fibers, but no experiments with $\alpha$-syn preamyloid oligomers were performed $(51,52)$. However, under the conditions employed, Hsp104 reduced ThT fluorescence of preformed $\alpha$-syn fibers by only $5 \%-20 \%$ after 24 hours of incubation $(51,52)$. This low level of potential fiber disassembly was not corroborated by other methods $(51,52)$. Remarkably, evidence was presented that Hsp104 degraded $\alpha$-syn (51). This is extraordinarily unlikely given that Hsp104 possesses no protease motifs or protease activity (27, $29,30,31,53,54)$. It is more probable that the findings of Kong et al. are due to a contaminating protease $(51,52)$. By contrast, we find absolutely no evidence of degradation of $\alpha$-syn by Hsp104 (Figure 6C). Rather, Hsp104 rapidly disassembles $\alpha$-syn fibers and preamyloid oligomers to yield soluble $\alpha$-syn.

It is not clear why Hsp104 has been lost from metazoa (28). Indeed, it is unclear whether mammalian cells express an analogous protein disaggregase able to solubilize large protein aggre- gates and restore protein functionality. Initial attempts to isolate such activity have been unsuccessful (40). The metazoan quality control machinery may be more optimized to prevent protein aggregation than reverse it and relies more heavily on the Hsp70 chaperone system. This system powerfully suppresses protein aggregation but only has limited ability to resolve even small soluble protein aggregates (27). Despite this, mammalian cells do have mechanisms to clear protein aggregates as revealed by silencing the gene encoding the aggregated protein (55). However, these pathways reflect autophagy and other protein degradation pathways rather than protein reactivation $(23,56)$. This general inability to rescue aggregated proteins may contribute to the lethality of excessive protein aggregation in animal cells.

Remodeling of $\alpha$-syn preamyloid oligomers and amyloid fibers by Hsp104 is surprising since $\alpha$-syn shares no sequence similarity with Hsp104's natural amyloidogenic substrates: Sup35, Ure2, and Rnq1 (57). Hence, Hsp104 may specifically engage and remodel generic aspects of the cross- $\beta$ amyloid form (41) and the distinct generic structure of preamyloid oligomers (14). However, S129E 
fibers were more resistant to disassembly. Thus, Hsp104 may need to initially engage $\alpha$-syn at amino acid 129, which is solvent accessible in assembled $\alpha$-syn fibers (58). Mutation of serine 129 to glutamate (but not alanine) may disrupt this interaction. Furthermore, E46K fibers were refractory to disassembly by Hsp104. This may reflect the different morphology of E46K fibers, which form compact bundles and meshwork arrays not observed with wild-type $\alpha$-syn (19).

In rescuing $\alpha$-syn neurotoxicity, Hsp104 reduced the number of $\alpha$-syn inclusions. By contrast, Hsp70 prevents dopaminergic neurodegeneration in $\alpha$-syn transgenic flies without affecting inclusion formation (24). Similar observations were reported for polyglutamine disorders, underscoring the limited ability of Hsp70 chaperones to remove aggregates (26). The lack of correlation between inclusion formation and neurodegeneration suggests that formation of inclusions may represent a protective cellular mechanism for sequestrating toxic assemblies (e.g., preamyloid oligomers) into safe inclusions. Indeed, expression of parkin, an E3 ubiquitin ligase connected with juvenile parkinsonism (5), prevents dopaminergic degeneration induced by $\mathrm{A} 30 \mathrm{P}$ in our rat lentiviral PD model, but this is accompanied by an increase in phosphorylated $\alpha$-syn inclusions (18). This suggests that Hsp104 reduces the number of inclusions in a manner that does not generate dangerous levels of toxic conformers, presumably because Hsp104 can disassemble these toxic species. Indeed, Hsp104's ability to safely disassemble protein aggregates is likely an adaptation that ensures cell survival and the dissolution of the entire aggregated proteome after environmental stress in yeast.

However, further study is needed to address whether Hsp104 reduces preamyloid oligomer levels in $\alpha$-syn expressing midbrain dopamine neurons. The low amount of preamyloid oligomers (relative to amyloid fibers), the low percentage of virally transduced cells, and the difficulty in isolating dopamine neurons from tissue extracts make the extraction of detectable levels of preamyloid oligomers very difficult. Further, we simultaneously expressed Hsp104 and $\alpha$-syn, and not Hsp104 after $\alpha$-syn aggregation, mainly due to technical issues. We have shown that coinjection of 2 viral vectors leads to more than $70 \%$ of cotransduced cells (18). In contrast, sequential injection of 2 viral vectors at 2 -week intervals increases the variability of targeting of nigral cells and greatly decreases the number of cotransduced cells (Lo Bianco et al., unpublished observations). This is due to the difficulty in performing 2 identical injections into the same brain at different times. Thus, further studies are required to assess whether Hsp104 reverses preformed $\alpha$-syn aggregates in vivo.

Overexpression of human $\alpha$-syn in yeast induces toxicity and cytoplasmic foci containing $\alpha$-syn (59). Surprisingly, Hsp104 overexpression has little effect on $\alpha$-syn toxicity in yeast (60). However, the $\alpha$-syn foci in yeast result from colocalization of $\alpha$-syn with a membrane compartment, which perturbs endoplasmic reticulum to Golgi transport and Rab-GTPase homeostasis $(61,62)$. That $\alpha$-syn does not form genuine aggregates in yeast, in contrast to the rat lentiviral model, explains why Hsp104 has little effect on its toxicity. It is likely that $\alpha$-syn toxicity in yeast mimics an early, underappreciated stage in $\mathrm{PD}$, prior to the accumulation of large quantities of preamyloid oligomers and fibers (61-63).

Even though not ordinarily expressed in mammalian cells, Hsp104 is extremely well tolerated in both tissue culture cells (including neurons) and in the brains of transgenic rodents and can perform beneficial protein-remodeling functions $(39,40,64-66)$.
Our studies demonstrate that Hsp104 combats $\alpha$-syn misfolding and associated dopaminergic degeneration in a rat model of PD. Hsp104's ability to prevent and reverse pathogenic protein aggregation should be considered as a potential strategy for treating or reversing $\mathrm{PD}$ and other protein aggregation diseases. However, further study is required to evaluate the safety of long-term Hsp104 expression in neurons.

\section{Methods}

Lentiviral vectors. cDNA coding for nuclear-localized YFP (BD Biosciences Clontech), A30P human $\alpha$-syn, and Hsp104 (kindly provided by D. Picard, Département de Biologie Cellulaire, Université de Genève, Genève, Switzerland) were cloned in the SIN-W-PGK lentiviral transfer vector, and viral particles (lenti-YFP, lenti-A30P, and lenti-Hsp104) were produced as described $(42,67)$. The viral suspensions lenti-A30P/lenti-YFP and lenti-A30P/lentiHsp104 were prepared by mixing viruses at 1:1 ratios (18). Particle content was matched to $180,000 \mathrm{ng}$ of $\mathrm{p} 24 / \mathrm{ml}$ for each lentiviral vector (18).

Stereotaxic injection. Lentiviral vectors were stereotaxically injected in the right substantia nigra of adult female Wistar rats (Iffa-Credo) weighing 200 g. Viral suspensions were injected at 2 sites with a $10-\mu l$ Hamilton syringe at a speed of $0.2 \mu \mathrm{l} / \mathrm{min}$ with an automatic injector (Stoelting Co.), and the needle was left in place for an additional 10 minutes before withdrawal. Stereotaxic injections were performed in 2 sites $(2.5 \mu \mathrm{l}$ per site) with anterior, lateral, and ventral coordinates $(4.8,2,7.7$, and 5.5, 1.7, 7.7) as described $(18,42)$. Animals were sacrificed at 6 weeks after injection. Experiments were carried out in accordance with the European Community Council directive (86/609/EEC) for the care and use of laboratory animals. The experiments described in this article were approved by the Veterinarian Office as well as by the Commission for Animal Experimentation of the Canton of Vaud (Switzerland) and were carried out under the animal license 1653 .

Immunohistochemistry. Animals were deeply anesthetized with sodium pentobarbital and perfused transcardially with $4 \%$ paraformaldehyde. Brains were removed and postfixed in $4 \%$ paraformaldehyde for approximately 24 hours, cryoprotected in $25 \%$ sucrose in $0.1 \mathrm{M}$ phosphate buffer for 48 hours, and processed as described $(18,42)$.

The following primary Abs were used: a TH sheep Ab (1:500; Pel-Freez Biologicals), the RG syn $\alpha$-syn polyclonal rabbit Ab (1:400; ref. 42), the LB509 human $\alpha$-syn specific monoclonal Ab (1:500; Zymed), the Pser129 Ab specifically recognizing phosphorylated Ser 129 of $\alpha$-syn (1:100; ref. 21), and a rabbit $\mathrm{Ab}$ to the $\mathrm{C}$-terminus of Hsp104 (1:800; Stressgen). For light microscopy, sections were stained by the classical avidin-biotin complex method as described (42). For multiple fluorescent labeling, the secondary Abs conjugated to Cy3 (donkey anti-sheep) and Cy5 (donkey anti-mouse) were from Jackson ImmunoResearch Laboratories. Hsp104 expression was revealed with a TSA fluorescein system (PerkinElmer Life Sciences). Sections were then analyzed by confocal microscopy (Leica TCS SP2 AOBS).

Silver staining was performed to detect degenerating neurons on paraformaldehyde-fixed sections $(18,47)$. The FD NeuroSilver kit was used according to the manufacturer's protocol (FD Neuro-Technologies).

Cell counting and TH fiber density. To determine the percentage of TH-IR cell loss in the substantia nigra, 9-10 coronal sections of 40- $\mu \mathrm{m}$ thickness per animal were stained by immunofluorescence for the TH marker. All TH-IR neurons were counted in the injected and noninjected side of the substantia nigra, and the results were expressed as the percentage of TH-IR cell loss relative to the noninjected side $(18,42,67)$. The borders of the substantia nigra were defined in the rostrocaudal axis using the anatomical landmarks in a rat brain atlas (68). Since the delineation of the borders between the ventral tegmental area (VTA) (A10), retrorubral nucleus (A8), and substantia nigra pars compacta (A9) are not clear, the medial border between VTA and sub- 
stantia nigra was defined by a vertical line passing through the medial tip of the cerebral peduncle (and by the medial terminal nucleus of the accessory nucleus of the optic tract, when present in the sections), thereby excluding the TH-IR cells in the VTA. The ventral border followed the dorsal border of the cerebral peduncle, thereby including the TH-IR cells in pars reticulata, and the area extended laterally to include the pars lateralis in addition to the pars compacta. The counting was carried out caudally until the pars reticulata disappeared, thus excluding the retrorubral nucleus. The sections used for quantification covered the entire substantia nigra from the rostral tip of the pars compacta back to the caudal end of the pars reticulata. Importantly, no significant difference was observed in the estimated volume of the substantia nigra using Cavalieri's principle or the size of the cell bodies of the counted neurons within experimental groups (noninjected versus injected side) or between experimental groups.

To determine the density of TH-IR terminals, striatal fibers were stained for $\mathrm{TH}$ with the $\mathrm{ABC}$ kit (Vector Laboratories), and the corresponding optical densities were evaluated with NIH IMAGE 1.4 software (http://rsbweb. nih.gov/nih-image/) $(18,42)$. For the numbers of neurons containing phosphorylated $\alpha$-syn inclusions, 5 sections throughout the substantia nigra were stained with the Pser129 Ab with the avidin-biotin complex method.

Statistics. Statistical analysis was performed by 1-way ANOVA, followed by a Scheffé's protected least significant difference (PLSD) post-hoc test (Statistica 5.1; Statsoft Inc.). The significance level was set at $P<0.05$.

Proteins. $\alpha$-syn bacterial expression plasmids were kindly provided by P. Lansbury (Brigham and Women's Hospital and Harvard Medical School, Cambridge, Massachusetts, USA). $\alpha$-syn proteins (wild type, A53T, A30P, E46K, S129A, and S129E) were purified as described (20). Hsp104 and Hsp104 ${ }^{\mathrm{K} 218 \mathrm{~T}: \mathrm{K} 620 \mathrm{~T}}$ were purified as described (33). Hsp104 concentrations refer to hexameric Hsp104. Hsc70, Hsp70, Hdj1, and Hdj2 were from Alexis Biochemicals.

$\alpha$-syn preamyloid oligomer purification and disassembly. $\alpha$-syn A30P preamyloid oligomers were purified by gel filtration (15). For disassembly experiments, A30P preamyloid oligomers $(0.5 \mu \mathrm{M}$ monomer) were incubated with either Hsp104 or Hsp104K218T:K620T $(10 \mu \mathrm{M})$ in KHM buffer $(40 \mathrm{mM}$ HEPES-KOH, pH 7.4, $150 \mathrm{mM} \mathrm{KCl,} 20 \mathrm{mM} \mathrm{MgCl} 2,1 \mathrm{mM} \mathrm{DTT}$ ) plus ATP $(10 \mathrm{mM})$ and an ATP regeneration system $(20 \mathrm{mM}$ creatine phosphate and $0.001 \mathrm{mg} / \mathrm{ml}$ creatine kinase) for 1 hour at $37^{\circ} \mathrm{C}$. Reactions were processed for dot blot (33) and probed with either anti-oligomer $\mathrm{Ab}$ (kindly provided by C. Glabe, University of California, Irvine, Irvine, California, USA) (14) or anti- $\alpha$-syn $\mathrm{Ab}$ (BD Biosciences). Alternatively, reactions were buffer exchanged using Bio-Gel P-6 spin columns into $40 \mathrm{mM}$ HEPES-KOH, $\mathrm{pH}$ 7.4, $150 \mathrm{mM} \mathrm{KCl}$, and $20 \mathrm{mM} \mathrm{NaEDTA}$, diluted 5-fold and incubated for 10 minutes at $25^{\circ} \mathrm{C}$ to disassemble Hsp104 hexamers, and processed for negative-stain EM (33). Other reactions were depleted of Hsp104 as described (33) and then fractionated through a Microcon YM-100 (100-kDa molecular weight cut off) filter (Millipore). Retentate and filtrate fractions were TCA precipitated and processed for SDS-PAGE followed by Coomassie Brilliant Blue staining.

$\alpha$-syn fiber assembly and disassembly. For fibrillization reactions, $\alpha$-syn proteins $(80 \mu \mathrm{M})$ were incubated in KHM plus ATP $(10 \mathrm{mM})$ and regeneration system plus or minus Hsp104 or Hsp104 K218T:K620T (0-1.6 $\mu \mathrm{M})$ for 0-48 hours at $37^{\circ} \mathrm{C}$, with rotation $(80 \mathrm{rpm}$ ) on a Mini-rotator (Glas-Col). Every 8 hours, reactions were supplemented with fresh regeneration system to maintain ATP levels.

For disassembly reactions, $\alpha$-syn fibers $(0.5 \mu \mathrm{M}$ monomer $)$ were incubated in KHM plus ATP $(10 \mathrm{mM})$ and regeneration system plus or minus Hsp104 or Hsp104 ${ }^{\mathrm{K} 218 \mathrm{~T}: \mathrm{K} 620 \mathrm{~T}}(10 \mu \mathrm{M})$ in the presence or absence of the indicated combinations of Hsp70, Hsc70, Hdj1, and Hdj2 (10 $\mu \mathrm{M})$ for 1 hour at $37^{\circ} \mathrm{C}$. In reactions containing AMP-PNP $(1 \mathrm{mM})$, the regeneration system was omitted.

Fiber assembly or disassembly was determined by ThT fluorescence, sedimentation analysis, turbidity, or EM $(8,33)$. For ThT fluorescence, ThT in $50 \mathrm{mM}$ glycine ( $\mathrm{pH} 8.5$ ) was added to give final concentrations of $\alpha$-syn $(0.25 \mu \mathrm{M})$ and ThT $(10 \mu \mathrm{M})$. Fluorescence at $480 \mathrm{~nm}$ was measured after excitation at $450 \mathrm{~nm}$. For sedimentation analysis, reactions were centrifuged at $436,000 \mathrm{~g}$ for 10 minutes at $25^{\circ} \mathrm{C}$. Supernatant and pellet fractions were then resolved by SDS-PAGE and stained with Coomassie Brilliant Blue. The percentage of $\alpha$-syn in the pellet was determined by densitometry and comparison to know quantities of $\alpha$-syn. Turbidity was monitored by absorbance at $395 \mathrm{~nm}$.

\section{Acknowledgments}

We thank D. Picard, P. Lansbury, and C. Glabe for generous provision of reagents; P. Colin, C. Sadeghi, and M. Rey for excellent technical assistance; A. Gitler for comments on the manuscript. C. Lo Bianco was supported by the Michael J. Fox Foundation, European Molecular Biology Organization, Swedish Parkinson Foundation, and the Swiss National Science Foundation. J. Shorter was supported by an American Heart Association Scientist Development Grant, University of Pennsylvania Institute on Aging pilot grant, and NIH Director's New Innovator Award (DP2OD002177). P. Aebischer was supported by the Michael J. Fox Foundation and the Swiss National Science Foundation.

Received for publication March 28, 2008, and accepted in revised form July 7, 2008.

Address correspondence to: Patrick Aebischer, Brain Mind Institute, SG-AAB 132 Ecole Polytechnique Fédérale de Lausanne (EPFL), Station 15, CH-1015 Lausanne, Switzerland. Phone: 4121-693-9505; Fax: 41-21-693-9510; E-mail: patrick.aebischer@ epfl.ch. Or to: James Shorter, Department of Biochemistry and Biophysics, University of Pennsylvania School of Medicine, 805b Stellar-Chance Laboratories, 422 Curie Boulevard, Philadelphia, Pennsylvania 19104, USA. Phone: (215) 573-4256; Fax: (215) 5734764; E-mail: jshorter@mail.med.upenn.edu.

Etienne Régulier's present address is: Novartis Pharma AG, Target $\&$ Lead Discovery Unit, CHBS, Basel, Switzerland.

Christophe Lo Bianco and James Shorter contributed equally to this work.

\footnotetext{
1. Skovronsky, D.M., Lee, V.M., and Trojanowski, J.Q. 2006. Neurodegenerative diseases: new concepts of pathogenesis and their therapeutic implications. Annu. Rev. Pathol. 1:151-170.

2. Dorsey, E.R., et al. 2007. Projected number of people with Parkinson's disease in the most populous nations, 2005 through 2030. Neurology. 68:384-386.

3. Braak, H., et al. 2003. Staging of brain pathology related to sporadic Parkinson's disease. Neurobiol. Aging. 24:197-211.
}

4. Spillantini, M.G., et al. 1997. Alpha-synuclein in Lewy bodies. Nature. 388:839-840.

5. Moore, D.J., West, A.B., Dawson, V.L., and Dawson, T.M. 2005. Molecular pathophysiology of Parkinson's disease. Annu. Rev. Neurosci. 28:57-87.

6. Davidson, W.S., Jonas, A., Clayton, D.F., and George, J.M. 1998. Stabilization of alpha-synuclein secondary structure upon binding to synthetic membranes. J. Biol. Chem. 273:9443-9449.

7. Conway, K.A., Harper, J.D., and Lansbury, P.T.
1998. Accelerated in vitro fibril formation by a mutant alpha-synuclein linked to early-onset Parkinson disease. Nat. Med. 4:1318-1320.

8. Conway, K.A., et al. 2000. Acceleration of oligomerization, not fibrillization, is a shared property of both alpha-synuclein mutations linked to earlyonset Parkinson's disease: implications for pathogenesis and therapy. Proc. Natl. Acad. Sci. U. S. A. 97:571-576.

9. Serpell, L.C., Berriman, J., Jakes, R., Goedert, M., 
and Crowther, R.A. 2000. Fiber diffraction of synthetic alpha-synuclein filaments shows amyloidlike cross-beta conformation. Proc. Natl. Acad. Sci. U. S. A. 97:4897-4902.

10. Crowther, R.A., Daniel, S.E., and Goedert, M. 2000. Characterisation of isolated alpha-synuclein filaments from substantia nigra of Parkinson's disease brain. Neurosci. Lett. 292:128-130.

11. Spillantini, M.G., et al. 1998. Filamentous alphasynuclein inclusions link multiple system atrophy with Parkinson's disease and dementia with Lewy bodies. Neurosci. Lett. 251:205-208.

12. Miake, H., Mizusawa, H., Iwatsubo, T., and Hasegawa, M. 2002. Biochemical characterization of the core structure of alpha-synuclein filaments. J. Biol. Chem. 277:19213-19219.

13. Neumann, M., et al. 2002. Misfolded proteinase K-resistant hyperphosphorylated alpha-synuclein in aged transgenic mice with locomotor deterioration and in human alpha-synucleinopathies. J. Clin. Invest. 110:1429-1439.

14. Kayed, R., et al. 2003. Common structure of soluble amyloid oligomers implies common mechanism of pathogenesis. Science. 300:486-489.

15. Lashuel, H.A., et al. 2002. Alpha-synuclein, especially the Parkinson's disease-associated mutants, forms pore-like annular and tubular protofibrils. J. Mol. Biol. 322:1089-1102.

16. Sharon, R., et al. 2003. The formation of highly soluble oligomers of alpha-synuclein is regulated by fatty acids and enhanced in Parkinson's disease. Neuron. 37:583-595.

17. Chen, L., and Feany, M.B. 2005. Alpha-synuclein phosphorylation controls neurotoxicity and inclusion formation in a Drosophila model of Parkinson disease. Nat. Neurosci. 8:657-663.

18. Lo Bianco, C., et al. 2004. Lentiviral vector delivery of parkin prevents dopaminergic degeneration in an alpha-synuclein rat model of Parkinson's disease. Proc. Natl. Acad. Sci. U. S. A. 101:17510-17515.

19. Choi, W., et al. 2004. Mutation E46K increases phospholipid binding and assembly into filaments of human alpha-synuclein. FEBS Lett. 576:363-368.

20. Fredenburg, R.A., et al. 2007. The impact of the E46K mutation on the properties of alpha-synuclein in its monomeric and oligomeric states. Biochemistry. 46:7107-7118.

21. Fujiwara, H., et al. 2002. alpha-Synuclein is phosphorylated in synucleinopathy lesions. Nat. Cell Biol. 4:160-164.

22. Norris, E.H., Giasson, B.I., Ischiropoulos, H., and Lee, V.M. 2003. Effects of oxidative and nitrative challenges on alpha-synuclein fibrillogenesis involve distinct mechanisms of protein modifications. J. Biol. Chem. 278:27230-27240.

23. Balch, W.E., Morimoto, R.I., Dillin, A., and Kelly, J.W. 2008. Adapting proteostasis for disease intervention. Science. 319:916-919.

24. Auluck, P.K., Chan, H.Y., Trojanowski, J.Q., Lee, V.M., and Bonini, N.M. 2002. Chaperone suppression of alpha-synuclein toxicity in a Drosophila model for Parkinson's disease. Science. 295:865-868.

25. Cummings, C.J., et al. 1998. Chaperone suppression of aggregation and altered subcellular proteasome localization imply protein misfolding in SCA1. Nat. Genet. 19:148-154.

26. Warrick, J.M., et al. 1999. Suppression of polyglutamine-mediated neurodegeneration in Drosophila by the molecular chaperone HSP70. Nat. Genet. 23:425-428.

27. Glover, J.R., and Lindquist, S. 1998. Hsp104, Hsp70, and Hsp40: a novel chaperone system that rescues previously aggregated proteins. Cell. 94:73-82.

28. Shorter, J. 2008. Hsp104: a weapon to combat diverse neurodegenerative disorders. Neurosignals. 16:63-74.
29. Wendler, P., et al. 2007. Atypical AAA+ subunit packing creates an expanded cavity for disaggregation by the protein-remodeling factor Hsp104. Cell. 131:1366-1377.

30. Parsell, D.A., Kowal, A.S., Singer, M.A., and Lindquist, S. 1994. Protein disaggregation mediated by heatshock protein Hsp104. Nature. 372:475-478.

31. Sanchez, Y., and Lindquist, S.L. 1990. HSP104 required for induced thermotolerance. Science. 248:1112-1115.

32. Sanchez, Y., Taulien, J., Borkovich, K.A., and Lindquist, S. 1992. Hsp104 is required for tolerance to many forms of stress. EMBO J. 11:2357-2364.

33. Shorter, J., and Lindquist, S. 2004 . Hsp104 catalyzes formation and elimination of self-replicating Sup35 prion conformers. Science. 304:1793-1797.

34. Shorter, J., and Lindquist, S. 2006. Destruction or potentiation of different prions catalyzed by similar Hsp104 remodeling activities. Mol. Cell. 23:425-438.

35. Doyle, S.M., et al. 2007. Asymmetric deceleration of $\mathrm{ClpB}$ or Hsp104 ATPase activity unleashes proteinremodeling activity. Nat. Struct. Mol. Biol. 14:114-122.

36. Narayanan, S., Walter, S., and Reif, B. 2006. Yeast prion-protein, sup35, fibril formation proceeds by addition and substraction of oligomers. Chembiochem. 7:757-765.

37. Savistchenko, J., Krzewska, J., Fay, N., and Melki, R. 2008. Molecular chaperones and the assembly of the prion Ure2p in vitro. J. Biol. Chem. 283:15732-15739.

38. Chernoff, Y.O., Lindquist, S.L., Ono, B., Inge-Vechtomov, S.G., and Liebman, S.W. 1995. Role of the chaperone protein Hsp104 in propagation of the yeast prion-like factor $\left[\mathrm{PSI}^{+}\right]$. Science. 268:880-884.

39. Dandoy-Dron, F., et al. 2006. Infection by ME7 prion is not modified in transgenic mice expressing the yeast chaperone Hsp104 in neurons. Neurosci. Lett. 405:181-185.

40. Mosser, D.D., Ho, S., and Glover, J.R. 2004. Saccharomyces cerevisiae $\mathrm{Hsp} 104$ enhances the chaperone capacity of human cells and inhibits heat stressinduced proapoptotic signaling. Biochemistry. 43:8107-8115.

41. Nelson, R., and Eisenberg, D. 2006. Structural models of amyloid-like fibrils. Adv. Protein Chem. 73:235-282.

42. Lo Bianco, C., Ridet, J.L., Schneider, B.L., Deglon, N., and Aebischer, P. 2002. alpha-Synucleinopathy and selective dopaminergic neuron loss in a rat lentiviral-based model of Parkinson's disease. Proc. Natl. Acad. Sci. U. S. A. 99:10813-10818.

43. Bao, Y.P., Cook, L.J., O’Donovan, D., Uyama, E., and Rubinsztein, D.C. 2002. Mammalian, yeast, bacterial, and chemical chaperones reduce aggregate formation and death in a cell model of oculopharyngeal muscular dystrophy. J. Biol. Chem. 277:12263-12269.

44. Kirik, D., et al. 2003. Nigrostriatal alpha-synucleinopathy induced by viral vector-mediated overexpression of human alpha-synuclein: a new primate model of Parkinson's disease. Proc. Natl. Acad. Sci. U. S. A. 100:2884-2889.

45. Kirik, D., et al. 2002. Parkinson-like neurodegeneration induced by targeted overexpression of alphasynuclein in the nigrostriatal system. J. Neurosci. 22:2780-2791.

46. Klein, R.L., King, M.A., Hamby, M.E., and Meyer, E.M. 2002. Dopaminergic cell loss induced by human A30P alpha-synuclein gene transfer to the rat substantia nigra. Hum. Gene Ther. 13:605-612.

47. Beltramino, C.A., de Olmos, J.S., Gallyas, F., Heimer, L., and Záborszky, L. 1993. Silver staining as a tool for neurotoxic assessment. NIDA Res. Monogr. 136:101-126; discussion 126-132.

48. Sandmann-Keil, D., Braak, H., Okochi, M., Haass, C., and Braak, E. 1999. Alpha-synuclein immuno- reactive Lewy bodies and Lewy neurites in Parkinson's disease are detectable by an advanced silverstaining technique. Acta Neuropathol. 98:461-464.

49. Schirmer, E.C., Queitsch, C., Kowal, A.S., Parsell, D.A., and Lindquist, S. 1998. The ATPase activity of Hsp104, effects of environmental conditions and mutations. J. Biol. Chem. 273:15546-15552.

50. Lashuel, H.A., Hartley, D., Petre, B.M., Walz, T., and Lansbury, P.T., Jr. 2002. Neurodegenerative disease: amyloid pores from pathogenic mutations. Nature. 418:291.

51. Kong, B., Chae, Y., and Lee, K. 2005. Degradation of wild-type alpha-synuclein by a molecular chaperone leads to reduced aggregate formation. Cell Biochem. Funct. 23:125-132.

52. Kong, B., Chae, Y.K., and Lee, K. 2003. Regulation of in vitro fibril formation of synuclein mutant proteins by Hsp104p. Protein Pept. Lett. 10:491-495.

53. Parsell, D.A., Sanchez, Y., Stitzel, J.D., and Lindquist, S. 1991 . Hsp104 is a highly conserved protein with two essential nucleotide-binding sites. Nature. 353:270-273.

54. Parsell, D.A., Taulien, J., and Lindquist, S. 1993. The role of heat-shock proteins in thermotolerance. $\mathrm{Pbi}$ los. Trans. R. Soc. Lond. B Biol. Sci. 339:279-286.

55. Yamamoto, A., Lucas, J.J., and Hen, R. 2000. Reversal of neuropathology and motor dysfunction in a conditional model of Huntington's disease. Cell. 101:57-66.

56. Martin-Aparicio, E., et al. 2001. Proteasomal-dependent aggregate reversal and absence of cell death in a conditional mouse model of Huntington's disease. J. Neurosci. 21:8772-8781.

57. Shorter, J., and Lindquist, S. 2005. Prions as adaptive conduits of memory and inheritance. Nat. Rev. Genet. 6:435-450.

58. Del Mar, C., Greenbaum, E.A., Mayne, L., Englander, S.W., and Woods, V.L., Jr. 2005. Structure and properties of alpha-synuclein and other amyloids determined at the amino acid level. Proc. Natl. Acad. Sci. U. S. A. 102:15477-15482.

59. Outeiro, T.F., and Lindquist, S. 2003. Yeast cells provide insight into alpha-synuclein biology and pathobiology. Science. 302:1772-1775.

60. Cashikar, A.G., Duennwald, M., and Lindquist, S.L. 2005. A chaperone pathway in protein disaggregation. Hsp26 alters the nature of protein aggregates to facilitate reactivation by Hsp104. J. Biol. Chem. 280:23869-23875.

61. Cooper, A.A., et al. 2006. Alpha-synuclein blocks ER-Golgi traffic and Rab1 rescues neuron loss in Parkinson's models. Science. 313:324-328.

62. Gitler, A.D., et al. 2008. The Parkinson's disease protein alpha-synuclein disrupts cellular Rab homeostasis. Proc. Natl. Acad. Sci. U. S. A. 105:145-150.

63. Gitler, A.D., and Shorter, J. 2007. Prime time for alpha-synuclein. J. Neurosci. 27:2433-2434.

64. Carmichael, J., et al. 2000. Bacterial and yeast chaperones reduce both aggregate formation and cell death in mammalian cell models of Huntington's disease. Proc. Natl. Acad. Sci. U. S. A. 97:9701-9705.

65. Perrin, V., et al. 2007. Neuroprotection by Hsp104 and Hsp27 in lentiviral-based rat models of Huntington's disease. Mol. Ther. 15:903-911.

66. Vacher, C., Garcia-Oroz, L., and Rubinsztein, D.C. 2005. Overexpression of yeast hsp104 reduces polyglutamine aggregation and prolongs survival of a transgenic mouse model of Huntington's disease. Hum. Mol. Genet. 14:3425-3433.

67. Deglon, N., et al. 2000. Self-inactivating lentiviral vectors with enhanced transgene expression as potential gene transfer system in Parkinson's disease. Hum. Gene Ther. 11:179-190.

68. Paxinos, G., and Watson, C. 1998. The rat brain in stereotaxic coordinates. 4th edition. Academic Press. San Diego, California, USA. 256 pp. 